\title{
Leptin controls the fate of fatty acids in isolated rat white adipocytes
}

\author{
W N William Jr, R B Ceddia ${ }^{\mathbf{1}}$ and $\mathbf{R}$ Curi \\ Departamento de Fisiologia e Biofísica, Instituto de Ciências Biomédicas, Universidade de São Paulo, Brasil \\ ${ }^{1}$ Departamento de Educação Física, Universidade Federal Fluminense, Rio de Janeiro, Brasil \\ (Requests for offprints should be addressed to R Curi, Departamento de Fisiologia e Biofísica, Instituto de Ciências Biomédicas, Av. Prof. Lineu Prestes, 1524, \\ CEP: 05508-900, São Paulo, Brasil; Email: ruicuri@fisio.icb.usp.br)
}

\begin{abstract}
Leptin directly increases the rate of exogenous glucose and fatty acids oxidation in isolated adipocytes. However, the effects of leptin on fatty acid metabolism in white adipose tissue have not been examined in detail. Here, we report that in adipocytes incubated for $6 \mathrm{~h}$ in the presence of leptin $(10 \mathrm{ng} / \mathrm{ml})$, the insulin-stimulated de novo fatty acid synthesis was inhibited by $36 \%(P<0 \cdot 05)$, while the exogenous oxidation of acetic and oleic acids was increased by $50 \%$ and $76 \%$ respectively. Interestingly, leptin did not alter the oxidation of intracellular fatty acids. Leptinincubated cells presented a 16-fold increase in the incorporation of oleic acid into triglyceride (TG) and a $123 \%$ increase in the intracellular TG hydrolysis (as measured by free fatty acids release). Fatty acid-TG cycling was not
\end{abstract}

affected by leptin. By employing fatty acids radiolabeled with ${ }^{3} \mathrm{H}$ and ${ }^{14} \mathrm{C}$, we could determine the concomitant influx of fatty acids (incorporation of fatty acids into TG) and efflux of fatty acids (intracellular fatty acids oxidation and free fatty acids release) in the incubated cells. Leptin increased by $30 \%$ the net efflux of fatty acids from adipocytes. We conclude that leptin directly inhibits de novo synthesis of fatty acids and increases the release and oxidation of fatty acids in isolated rat adipocytes. These direct energy-dissipating effects of leptin may play an important role in reducing accumulation of fatty acids into TG of rat adipose cells.

Journal of Endocrinology (2002) 175, 735-744

\section{Introduction}

Leptin has been implicated in body weight regulation through its central effects on the hypothalamus (Friedman \& Halaas 1998). However, the presence of the leptin receptor $(\mathrm{OB}-\mathrm{R})$ in peripheral tissues intimately involved in the intermediary metabolism, such as skeletal muscle, adipocytes, pancreatic islets and liver (Luoh et al. 1997), indicate that these tissues are also targets for the action of leptin. In the early pair feeding studies, it was demonstrated that leptin has weight reducing effects in excess of those mediated through its central nervous system action (Levin et al. 1996). Subsequently, Barzilai et al. (1999) observed that animals previously treated with leptin present an increase in glucose uptake and glycogen synthesis in peripheral tissues during insulinemic clamp as compared with food-restricted littermates.

We have previously demonstrated that leptin increases glucose uptake and decarboxylation and glycogen synthesis in incubated soleus muscle (Ceddia et al. 1999c). Leptin also inhibits glycogenolysis and gluconeogenesis in isolated hepatocytes (Ceddia et al. 1999a) and modulates insulin secretion by perifused pancreatic islets (Ceddia et al. 1999b). Chronic exposure (15 h culture) of isolated adipocytes to leptin has been reported to increase basal and insulin-induced glucose decarboxylation and to inhibit insulin-stimulated glucose uptake and incorporation into lipids (Müller et al. 1997, Ceddia et al. 1998). Leptin seems to up-regulate Krebs' cycle activity in these cells, as could be concluded by an increase in acetic acid oxidation and citrate synthase maximal activity (Ceddia et al. 2000).

In spite of the increasing interest in the direct actions of leptin on adipocytes, its possible effects on the metabolism of fatty acids in these cells have not been fully characterized. Previous studies suggest that, at least in rodents, these actions do occur and might play an important role in the overall weight reducing effect of leptin. Evidence for a paracrine/autocrine effect of leptin on lipolysis (i.e. glycerol release) of adipose tissue has been obtained from in vivo (Frühbeck et al. 1998) and in vitro (Frühbeck et al. 1997) studies. Zhou et al. (1999) demonstrated that adenovirus-induced hyperleptinemia leads to an increase in the expression of enzymes of fatty acid oxidation, such as acyl-CoA oxidase (ACO) and carnitine palmitoyl transferase 1 (CPT), accompanied by a complete depletion of triglyceride (TG) in adipose tissues without a concomitant increase in the concentration of circulating free fatty acids (FFA) (Shimabukuro et al. 1997, Zhou et al. 1999). Such a phenomenon was attributed to a putative increase in intracellular fatty acid oxidation produced by leptin 
(Shimabukuro et al. 1997). The same research group reported the disappearance of ectopic denervated adipose tissue using the same hyperleptinemic animal model, suggesting that leptin has a direct effect on these cells (Wang et al. 1999c). Furthermore, in incubated isolated adipocytes, leptin up-regulates the expression of ACO, $\mathrm{CPT}$, uncoupling protein 2 (UCP-2) and peroxisome proliferator activated receptor alpha (PPAR- $\alpha$ ), all of which are involved in lipid oxidation (Wang et al. 1999a, Ceddia et al. 2000).

Recently, it has been proposed that leptin at supraphysiological concentrations is unable to cross the bloodbrain barrier so as to further increase its central nervous system levels and action (Wang et al. 1999b). Nevertheless, fat mass is still reduced in animals made hyperleptinemic by adenovirus infection. According to these studies, there must be a mechanism by which leptin prevents fat accumulation independently of the hypothalamus (Wang et al. 1999b). The elucidation of these mechanisms might be important for the future use of exogenous leptin to treat human obesity, a condition where central resistance to leptin is thought to occur (Friedman \& Halaas 1998).

White adipose tissue is estimated to store $95 \%$ of total body TG and plays a central role in the development of obesity (Coppack et al. 1994). White fat cells express leptin receptors and are metabolically responsive to this hormone. Therefore, the aim of the present study was to investigate the effects of leptin on fatty acid metabolism in isolated adipocytes. The following parameters were measured in incubated cells in the presence of leptin: de novo fatty acid synthesis from glucose, comparison of long chain (oleic acid) and short chain (acetic acid) exogenous fatty acid oxidation, incorporation of oleic acid into TG, fatty acid-TG cycling, intracellular fatty acid oxidation and TG hydrolysis. The net influx and efflux of fatty acids were also determined. Evidence for a direct peripheral effect of leptin on adipose tissue reducing fat accumulation is provided.

\section{Materials and Methods}

\section{Experimental animals}

Male lean albino rats (Wistar strain) weighing 150-180 g were maintained on a $12 \mathrm{~h}$ light $/ 12 \mathrm{~h}$ darkness cycle at $22{ }^{\circ} \mathrm{C}$ and fed a standard laboratory chow which was available ad libitum. Ethics approval was granted for these studies by the Institute of Biomedical Science, Animal Experimental Committee, University of São Paulo.

\section{Cell isolation and washing procedures}

White adipocytes were isolated as previously described (Rodbell 1964). Briefly, rats were killed by cervical dislocation, the epididymal fat pads were removed under sterile conditions and pooled. Isolated cells were obtained by shaking (150 orbitals per min) finely minced tissues $(2-4 \mathrm{~g})$ in $4 \mathrm{oz}$ sterile polypropylene containers at $37^{\circ} \mathrm{C}$ for $15-30 \mathrm{~min}$ in $10 \mathrm{ml}$ DMEM containing Hepes $(25 \mathrm{mM})$, type II collagenase $(1.25 \mathrm{mg} / \mathrm{ml})$ and $4 \%$ BSA. Cells were then filtered through nylon mesh and washed three times in Krebs-Ringer sodium bicarbonate buffer (KRB). Cell density (volume of cells/volume of cell suspension) was determined as previously described (DiGirolamo et al. 1971).

\section{Cell incubation}

After washing, $1 \mathrm{ml}$ cell suspension $(10 \%$ lipocrit, $4-5 \times 10^{5}$ cells) was incubated for $6 \mathrm{~h}$, at $37^{\circ} \mathrm{C}$, in $20 \mathrm{ml}$ plastic scintillation flasks in KRB saturated with carbogen $\left(\mathrm{O}_{2} / \mathrm{CO}_{2}, 95 / 5 \%\right), \mathrm{pH} 7 \cdot 4$, containing defatted BSA $(1 \cdot 0-1 \cdot 5 \%)$ and specific additions according to the metabolic parameter to be determined (Table 1). Leptin $10 \mathrm{ng} / \mathrm{ml}$ (Amgen Inc., Thousand Oaks, CA, USA) and/or insulin $10000 \mu \mathrm{U} / \mathrm{ml}$ (Sigma Chemical Co., St Louis, MO, USA) were added where indicated. In all experiments where oleic acid was used (radiolabeled or not), it had previously been complexed with defatted BSA (2:1 ratio) by overnight incubation and vigorous shaking at $37^{\circ} \mathrm{C}$ (Ceddia et al. 2000).

\section{De novo fatty acid synthesis}

After the incubation period, $0.3 \mathrm{ml} \mathrm{H}_{2} \mathrm{SO}_{4}(4 \mathrm{M})$ was added to the incubation medium and lipids were extracted with isopropanol/n-heptane $/ \mathrm{H}_{2} \mathrm{SO}_{4}(4: 1: 0 \cdot 25, \mathrm{v} / \mathrm{v} / \mathrm{v})$ as previously described (Dole \& Meirnertz 1960). The lipid phase was separated and dried, resuspended in ethanolic $\mathrm{KOH}$ solution ( $1 \mathrm{ml}$ saturated $\mathrm{KOH}$ per $100 \mathrm{ml} 95 \%$ ethanol) and saponified for $1 \mathrm{~h}$ at $37^{\circ} \mathrm{C}$ with vigorous shaking. Lipids were then re-extracted with hexane. The radioactivity present in this fraction was determined and represents the incorporation of $\left[\mathrm{U}_{-}{ }^{14} \mathrm{C}\right] \mathrm{D}$-glucose into the fatty acid moiety of TG (Rodbell 1964).

\section{$\left[1-{ }^{14} \mathrm{C}\right]$ Acetic and $\left[1-{ }^{14} \mathrm{C}\right]$ oleic acid oxidation}

The $20 \mathrm{ml}$ scintillation flasks for incubation of adipocytes had a centered-isolated well containing a loosely folded piece of filter paper moistened with $0.2 \mathrm{ml}$ 2-phenylethylamine/methanol (1:1, v/v). After the 6-h incubation period, the medium was acidified with $0.3 \mathrm{ml}$ $\mathrm{H}_{2} \mathrm{SO}_{4}(4 \mathrm{M})$, the flasks were maintained sealed and were incubated for a further $60 \mathrm{~min}$. At the end of this period, the radioactivity trapped in the filter paper was determined and represents the conversion of $\left[1-{ }^{14} \mathrm{C}\right]$ acetic acid/ $\left[1-{ }^{14} \mathrm{C}\right]$ oleic acid into ${ }^{14} \mathrm{CO}_{2}$ (Ceddia et al. 2000).

\section{Incorporation of $\left[1-{ }^{14}\right.$ C]oleic acid into $T G$}

After the 6-h incubation period, $0 \cdot 3 \mathrm{ml} \mathrm{H}_{2} \mathrm{SO}_{4}(4 \mathrm{M})$ was added to the incubation medium and lipids were extracted 


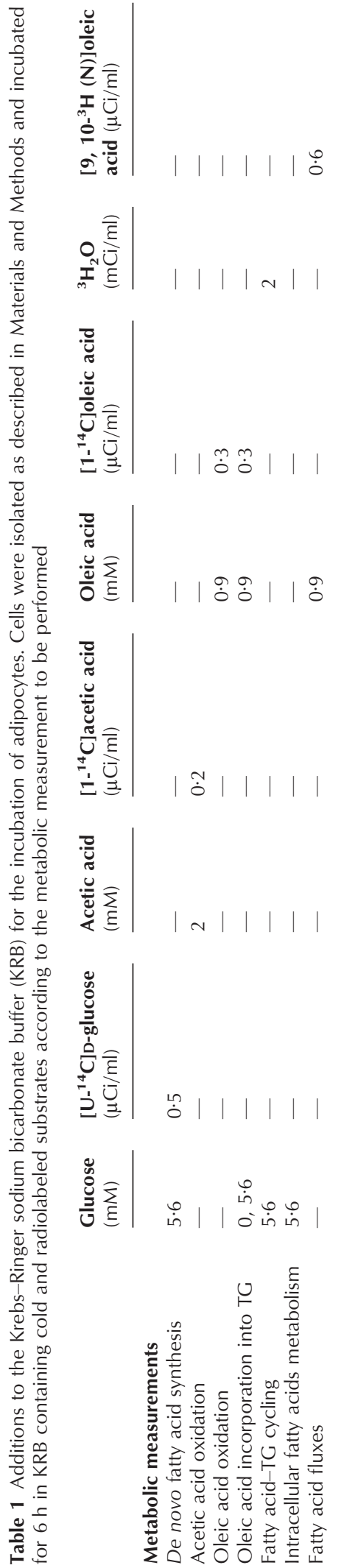

www.endocrinology.org with isopropanol/n-heptane $/ \mathrm{H}_{2} \mathrm{SO}_{4}(4: 1: 0 \cdot 25, \mathrm{v} / \mathrm{v} / \mathrm{v})$ as previously described (Dole \& Meirneirtz 1960). The lipid phase was separated and dried, resuspended in chloroform/ methanol $(2: 1, \mathrm{v} / \mathrm{v})$ and submitted to thin layer chromatography for lipid fractions separation. The mobile phase consisted of a hexane/diethylic ether/acetic acid solution (70:30:1, v/v/v) (Homem de Bitencourt \& Curi 1998). The radioactivity present in the TG fraction of each sample was then determined.

Fatty acid-TG cycling

After the incubation period, $0.3 \mathrm{ml} \mathrm{H}_{2} \mathrm{SO}_{4}(4 \mathrm{M})$ was added to the incubation medium and lipids were extracted with an isopropanol/n-heptane $/ \mathrm{H}_{2} \mathrm{SO}_{4}(4: 1: 0 \cdot 25, \mathrm{v} / \mathrm{v} / \mathrm{v})$ mixture as previously described (Dole \& Meirneirtz 1960). The lipid phase was separated and dried, resuspended in ethanolic $\mathrm{KOH}$ solution $(1 \mathrm{ml}$ saturated $\mathrm{KOH}$ per $100 \mathrm{ml}$ $95 \%$ ethanol) and saponified for $1 \mathrm{~h}$ at $37^{\circ} \mathrm{C}$ with vigorous shaking. Lipids were then re-extracted with hexane. The radioactivity present in the ethanolic and hexane phases was determined and represents the ${ }^{3} \mathrm{H}$-glycerol moiety of TG and the ${ }^{3} \mathrm{H}$-fatty acid moiety of TG synthesized from glucose respectively (Rodbell 1964). It was assumed, for the calculation of TG and fatty acid synthesis, that the specific activity of water in the adipocyte was identical to the one in the incubation flask and that each glycerol incorporated into TG contained $3 \cdot 3$ atoms of tritium and that each fatty acid incorporated into TG contained $13 \cdot 3$ atoms of tritium (Jungas 1968). The rate of incorporation of free fatty acids into TG is three times the rate of incorporation of glycerol phosphate into TG; this results from the fact that three fatty acids are esterified to one glycerol phosphate molecule to form one TG molecule. Fatty acids incorporated into TG were either newly synthesized from glucose (and thus are ${ }^{3} \mathrm{H}$-radiolabeled) or derived from intracellular TG breakdown (and thus are not ${ }^{3} \mathrm{H}$-radiolabeled and represent fatty acid-TG cycling). Therefore, fatty acid-TG cycling can be calculated by the following equation (Brooks et al. 1982, Tagliaferro et al. 1990):

Cycling $=\left[3 \times\left({ }^{3} \mathrm{H}\right.\right.$-glycerol synthesis $\left.)\right]-$

$\left[\left({ }^{3} \mathrm{H}\right.\right.$-fatty acid synthesis $\left.)\right]$

\section{Radiolabeling of adipocytes}

For the study of intracellular fatty acids metabolism and fluxes, cells were radiolabeled with $\left[1-{ }^{14} \mathrm{C}\right]$ oleic acid before the 6-h incubation period. After isolation and washing, cells were incubated for $1 \mathrm{~h}$, at $37^{\circ} \mathrm{C}$, in $50 \mathrm{ml}$ sterile polypropylene tubes, with cells floating on top (forming a thin cell layer) of $25 \mathrm{ml}$ DMEM containing Hepes $(20 \mathrm{mM})$, fetal bovine serum (5\%), glucose (8.7 mM), penicillin/streptomycin $(20 \mathrm{U} / \mathrm{ml} / 20 \mathrm{mg} / \mathrm{ml})$, and $\left[1-{ }^{14} \mathrm{C}\right]$ oleic acid $(100 \mu \mathrm{Ci} / \mathrm{ml})$ previously complexed 
with defatted BSA (1.5\%). After the radiolabeling period, cells were washed three times with KRB and incubated as described in a previous section (Cell incubation).

An aliquot of these cells was separated before incubation and submitted to lipid extraction with isopropanol/ n-heptane $/ \mathrm{H}_{2} \mathrm{SO}_{4}(4: 1: 0 \cdot 25, \mathrm{v} / \mathrm{v} / \mathrm{v})$. Thin layer chromatography was performed and the radioactivity present in each lipid fraction was determined (Dole \& Meirneirtz 1960, Homen de Bitencourt \& Curi 1998). The majority of $\left[1-{ }^{14} \mathrm{C}\right]$ oleic acid was incorporated into triglyceride (70\%). Polar lipids (mono and diacylglycerol) accounted for $20 \%$ of the intracellular radiolabeled lipids. The remaining $10 \%$ of the $\left[1-{ }^{14} \mathrm{C}\right]$ oleic acid incorporated was found in the free fatty acid and phospholipid fractions. Therefore, medium contamination with unwashed $\left[1-{ }^{14} \mathrm{C}\right]$ oleic acid was assumed to be negligible.

Since the majority of $\left[1-{ }^{14} \mathrm{C}\right]$ oleic acid was incorporated into TG, the radioactivity present in $\mathrm{CO}_{2}$ or medium's free fatty acid measured during the subsequent incubation was considered to be mainly derived from intracellular TG. Previous studies have provided evidence that, at least during fasting, intracellular TGs are metabolized in a non-specific pattern; i.e. the five most abundant fatty acids in adipose tissue (palmitic, palmitoleic, stearic, oleic and linoleic) are mobilized from TG in the same proportion as their original content in TG molecules (Stein \& Stein 1962). Therefore, the metabolism of intracellular $\left[1-{ }^{14} \mathrm{C}\right]$ oleic acid incorporated into TG was assumed to be representative of the metabolism of all fatty acids esterified o TG inside the cell.

\section{Intracellular fatty acid metabolism}

Previously radiolabeled adipocytes (average of 140000 c.p.m. $/ 4-5 \times 10^{5}$ cells/flask) were incubated for $6 \mathrm{~h}$ in $20 \mathrm{ml}$ scintillation flasks with the additions to the medium as described in Table 1 . After the 6-h incubation period, the medium was acidified with $0.3 \mathrm{ml} \mathrm{H}_{2} \mathrm{SO}_{4}$ $(4 \mathrm{M})$, the flasks were maintained sealed and incubated for a further $60 \mathrm{~min}$. At the end of this period, the radioactivity trapped in the filter paper was determined. For the analysis of intracellular lipid hydrolysis (i.e. TG hydrolysis, mainly), adipocytes from the same pool were incubated for $6 \mathrm{~h}$ in plastic test tubes and periodically agitated. At the end of the incubation period, the tubes were centrifuged so as to separate the cells from the incubation medium. An aliquot of the infranatant was separated for lipid extraction and thin layer chromatographic analysis (as described above). The radioactivity present in the free fatty acid fraction was determined and represents TG hydrolyzed and released to the incubation medium. Non-specific free fatty acid released from the cells (due to cell lysis or unwashed $\left[1-{ }^{14} \mathrm{C}\right]$ oleic acid contamination) was determined and discounted for each sample by rapid centrifugation and lipid extraction from the medium at time zero of incubation.

\section{Fatty acid fluxes}

Incubation of adipocytes was performed as described for the study of intracellular fatty acids metabolism, except for the absence of glucose in the incubation medium and the addition of cold $(0.9 \mathrm{mM})$ and labeled $(0.6 \mu \mathrm{Ci} / \mathrm{ml})$ $\left[9,10-{ }^{3} \mathrm{H}(\mathrm{N})\right]$ oleic acid (Table 1$)$. This procedure allowed us to study the influx of $\left[{ }^{3} \mathrm{H}\right]$ oleic acid and efflux of $\left[{ }^{14} \mathrm{C}\right]$ oleic acid in the same cell pool. After the 6-h incubation period, the incorporation of ${ }^{14} \mathrm{C}$ radioactivity into ${ }^{14} \mathrm{CO}_{2}$ and into medium free fatty acids was determined, as well as the incorporation of $\left[9,10-{ }^{3} \mathrm{H}(\mathrm{N})\right]$ oleic acid into TG, as described in the previous sections.

For the calculation of fatty acid influx and efflux of the adipocyte in absolute values (nmol/10 $10^{5}$ cells), the specific activity of $\left[1-{ }^{14} \mathrm{C}\right]$ oleic acid in the intracellular compartment was determined. Since $\left[{ }^{14} \mathrm{C}\right]$ oleic acid was mainly incorporated into $\mathrm{TG},{ }^{14} \mathrm{C}$ radioactivity present in medium free fatty acids and $\mathrm{CO}_{2}$ was assumed to be derived 100\% from intracellular TG. The intracellular $\left[{ }^{14} \mathrm{C}\right]$ oleic acid incorporated was considered to be representative of the whole fatty acid moiety of intracellular TG. As discussed in the section above, adipocytes seem to mobilize intracellular TG in a non-specific pattern (Stein \& Stein 1962). Therefore, the metabolism of incorporated $\left[{ }^{14} \mathrm{C}\right]$ oleic acid reflects all intracellular TG's fatty acids mobilized from control and leptin-treated cells. The specific activity of $\left[1-{ }^{14} \mathrm{C}\right]$ oleic acid (i.e. ${ }^{14} \mathrm{C}$-fatty acids) in the intracellular compartment of the adipocytes was determined as follows: an aliquot of the cell's lipid extract obtained before incubation was separated, dried, resuspended in reaction medium and the total TG content was measured using Merck's Ecoline 25 Triglyceride kit (Merck, Brazil) for plasmatic determinations (McGowan et al. 1983). Since each TG molecule contains three fatty acids, multiplying the intracellular TG concentration by 3 assessed the intracellular amount of fatty acids esterified to TG. This value was used for the estimation of intracellular dilution of $\left[{ }^{14} \mathrm{C}\right]$ oleic acid and, therefore, for the calculation of its specific activity in the intracellular milieu. The flux of fatty acids was then determined by the following equations:

Fatty acid influx $=$ incorporation of $\left[9,10-{ }^{3} \mathrm{H}(\mathrm{N})\right]$ oleic acid into TG

Fatty acid efflux $=$ (incorporation of $\left[1-{ }^{14} \mathrm{C}\right]$ oleic acid equivalents into $\left.{ }^{14} \mathrm{CO}_{2}\right)+$ (incorporation of $\left[1-{ }^{14} \mathrm{C}\right]$ oleic acid equivalents into medium free fatty acids)

\section{Statistical analysis}

Statistical analysis was performed by one-way ANOVA with Tukey-Kramer multiple comparison test or Student's unpaired $t$-test. The level of significance was set at $P<0 \cdot 05$. 


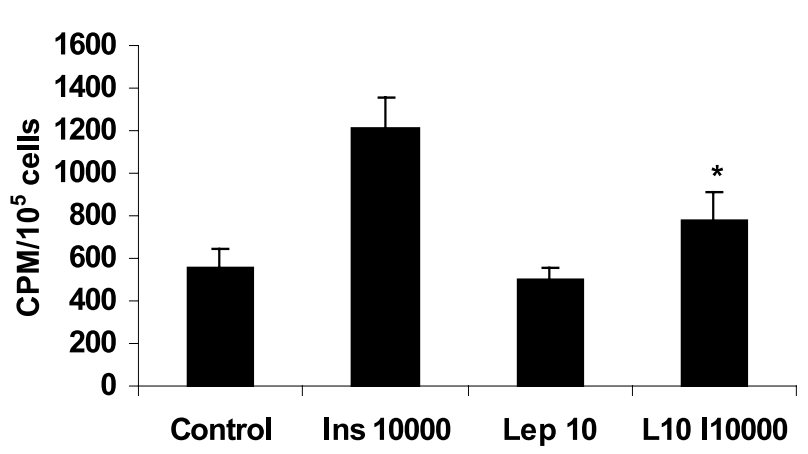

Figure 1 Effect of insulin, leptin and leptin plus insulin on de novo fatty acid synthesis from glucose in adipocytes. Control=no leptin/no insulin; Ins $10000=$ insulin $10000 \mu \mathrm{U} / \mathrm{ml}$; Lep $10=$ leptin $10 \mathrm{ng} / \mathrm{ml}$ L L10 I10000=leptin $10 \mathrm{ng} / \mathrm{ml}$ plus insulin $10000 \mu \mathrm{U} / \mathrm{ml}$. Data are expressed as means \pm S.E.M. of 10 determinations; ${ }^{*} P<0 \cdot 05$ vs Ins 10000.

\section{Results}

Effect of insulin, leptin and insulin plus leptin on de novo fatty acid synthesis

In the presence of $10 \mathrm{ng} / \mathrm{ml}$ leptin, no significant alteration was observed in the basal incorporation of $\left[\mathrm{U}_{-}{ }^{14} \mathrm{C}\right] \mathrm{D}$-glucose into the fatty acid moiety of TG in isolated adipocytes. Insulin at a supraphysiological concentration $(10000 \mu \mathrm{U} / \mathrm{ml})$ elicited a $117 \%$ increase in de novo lipogenesis. However, this effect of insulin was significantly reduced by $36 \%$ when the adipocytes were incubated in the presence of both insulin and leptin (Fig. 1).

Effect of leptin on $\left[1-{ }^{14}\right.$ C]acetic and $\left[1-{ }^{14}\right.$ C]oleic acid oxidation

Leptin $(10 \mathrm{ng} / \mathrm{ml})$ increased $\left[1-{ }^{14} \mathrm{C}\right]$ acetic acid oxidation by $50 \%$ in isolated adipocytes (Fig. 2A). Under the same incubation conditions (i.e. in the absence of glucose or insulin in the incubation medium), leptin stimulated exogenous oleic acid oxidation to a greater extent than that observed for the short chain fatty acid, reaching up to $76 \%$ higher values of $\left[1-{ }^{14} \mathrm{C}\right]$ oleic acid conversion to ${ }^{14} \mathrm{CO}_{2}$ as compared with control (Fig. 2B).

Effect of glucose, leptin and insulin on $\left[1-{ }^{14} \mathrm{C}\right]$ oleic acid incorporation into TG

As expected, the addition of glucose $(5.6 \mathrm{mM})$ to the incubation medium led to a 2- to 6-fold increase in the incorporation of $\left[1-{ }^{14} \mathrm{C}\right]$ oleic acid into TG in both the control and the stimulated groups (insulin $10000 \mu \mathrm{U} / \mathrm{ml}$ or leptin $10 \mathrm{ng} / \mathrm{ml}$ ). In the absence of glucose, insulin $(10000 \mu \mathrm{U} / \mathrm{ml})$ elicited an 11-fold increase in TG synthesis as compared with control. Leptin $(10 \mathrm{ng} / \mathrm{ml})$, however, up-regulated the flux of exogenous FFA to TG to a greater extent than insulin, promoting TG synthesis values 17-fold higher than the unstimulated group. In the presence of glucose $(5.6 \mathrm{mM})$, the stimulating effects of insulin and leptin were maintained: insulin $(10000 \mu \mathrm{U} / \mathrm{ml})$ and leptin $(10 \mathrm{ng} / \mathrm{ml})$ enhanced the incorporation of $\left[1-{ }^{14} \mathrm{C}\right]$ oleic acid into TG by 11 and 7 times respectively (Fig. 3).

Effect of insulin, leptin and insulin plus leptin on fatty acid-TG cycling

As previously described (Brooks et al. 1982), insulin $(10000 \mu \mathrm{U} / \mathrm{ml})$ did not alter fatty acid-TG cycling in adipocytes. No effect of leptin $(10 \mathrm{ng} / \mathrm{ml})$ or insulin plus leptin could be detected on this metabolic parameter (Table 2).

\section{Effect of leptin on intracellular fatty acid metabolism}

Experiments were carried out in the presence of glucose $(5.6 \mathrm{mM})$ and in the absence of oleic acid in the incubation medium. Under these conditions, leptin $(10 \mathrm{ng} / \mathrm{ml})$ was unable to modify the oxidation of fatty acids arising from the hydrolysis of intracellular TG in isolated
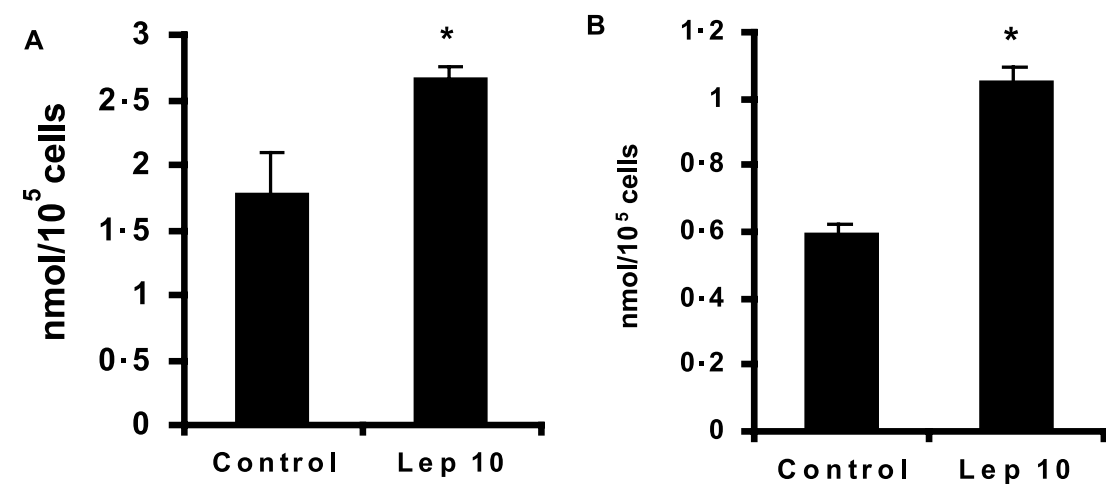

Figure 2 Effect of leptin on (A) $\left[1-{ }^{14} \mathrm{C}\right]$ acetic acid oxidation and (B) $\left[1-{ }^{14} \mathrm{C}\right]$ oleic acid oxidation in adipocytes. Control $=$ no leptin/no insulin; Lep $10=$ leptin $10 \mathrm{ng} / \mathrm{ml}$. Data are expressed as means \pm S.E.M. of 10 determinations. ${ }^{\star} P<0 \cdot 05$ compared with Control. 


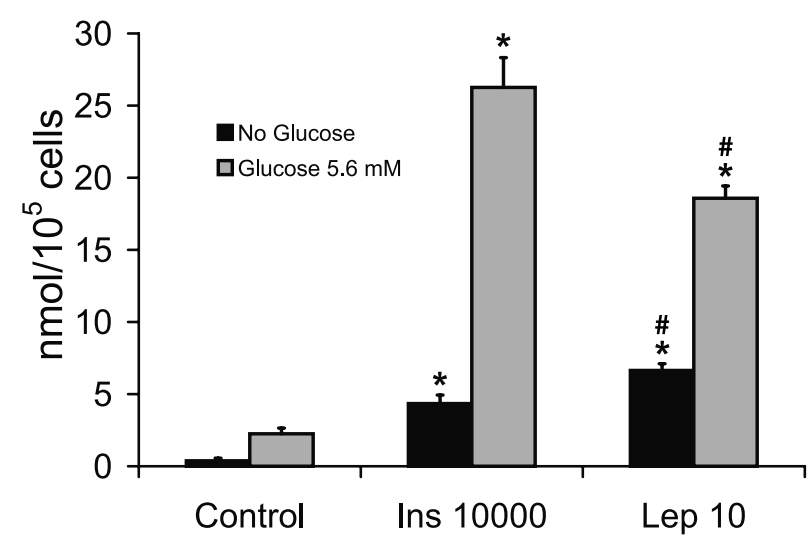

Figure 3 Effect of insulin and leptin on $\left[1-{ }^{14} \mathrm{C}\right]$ oleic acid incorporation into TG in adipocytes in the absence or presence of glucose $(5.6 \mathrm{mM})$. Control= no leptin/no insulin; Ins $10000=$ insulin $10000 \mu \mathrm{U} / \mathrm{ml}$; Lep $10=$ leptin $10 \mathrm{ng} / \mathrm{ml}$. Data are expressed as means \pm S.E.M. of 4 determinations. ${ }^{*} P<0 \cdot 05$ compared with respective Control groups. ${ }^{\# P}<0.05$ compared with respective Ins 10000 groups.

Table 2 Effect of insulin, leptin and leptin plus insulin on fatty acid-TG cycling in adipocytes. Control=no leptin/no insulin. Data are expressed as means \pm S.E.M. of 10 determinations

Fatty acid-TG cycling (nmol/10 $10^{5}$ cells)

\section{Group}

Control

Insulin $(10000 \mu \mathrm{U} / \mathrm{ml})$

Leptin $(10 \mathrm{ng} / \mathrm{ml})$

$63 \cdot 94 \pm 5 \cdot 37$

$49 \cdot 28 \pm 11 \cdot 96$

$55 \cdot 06 \pm 4 \cdot 56$

Leptin $(10 \mathrm{mg} / \mathrm{ml})+$ insulin $(10000 \mu \mathrm{U} / \mathrm{ml})$

$55 \cdot 25 \pm 2 \cdot 70$ adipocytes (Fig. 4A). However, it is noteworthy that leptin increased by $123 \%$ the release of free fatty acids to the incubation medium, reflecting a stimulation of TG hydrolysis (Fig. 4B).

\section{Effect of leptin on fatty acid fluxes}

Experiments were carried out in the absence of glucose and in the presence of oleic acid $(0.9 \mathrm{mM})$ in the incubation medium. Under these conditions, no differences were observed in the oxidation of intracellular fatty acids between the control and the leptin-treated groups (Fig. 5B). Leptin $(10 \mathrm{ng} / \mathrm{ml})$ stimulated free fatty acid release to the incubation medium by $38 \%$ (Fig. 5C). As expected leptin also raised - by $2 \cdot 8$-fold - the incorporation of exogenous $\left[9,10-{ }^{3} \mathrm{H}(\mathrm{N})\right]$ oleic acid into TG in these cells (Fig. 5A). Under these incubation conditions, the efflux of fatty acids exceeded the influx in both control and leptin-treated cells. However, leptin $(10 \mathrm{ng} / \mathrm{ml})$ exerted a more pronounced efflux- than influx-stimulating effect (considering absolute values, in nmol $/ 10^{5}$ cells of fatty acids metabolized), thus resulting in higher net fatty acid efflux as compared with control $\left(145 \cdot 6 \mathrm{nmol} / 10^{5}\right.$ cells versus $111.6 \mathrm{nmol} / 10^{5}$ cells respectively) (Fig. 5D).

\section{Discussion}

Treatment of mice with leptin alters the morphology and function of white adipose tissue, resulting in dramatic body fat reduction. Such changes include atropy of adipocytes, shrinkage of intracellular lipid droplets, increased number of mitochondria and, under higher circulating leptin concentrations, complete disappearance of TG and even of the white adipose tissue itself (Sarmiento et al. 1997, Shimabukuro et al. 1997). Two possible direct mechanisms of leptin action on adipocytes may explain these in vivo observations: decreased TG synthesis (either de novo fatty acid synthesis and/or fatty acid esterification into TG) and increased TG breakdown (either fatty acid oxidation and/or fatty acid exportation to non-adipose cells).

In the present study, leptin $(10 \mathrm{ng} / \mathrm{ml})$ was found to decrease insulin-stimulated de novo fatty acid synthesis
A

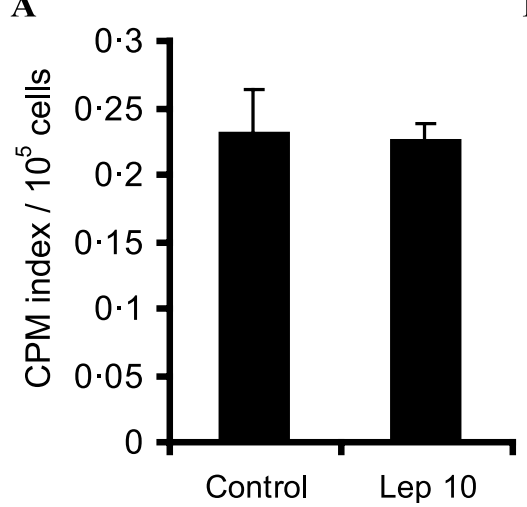

B

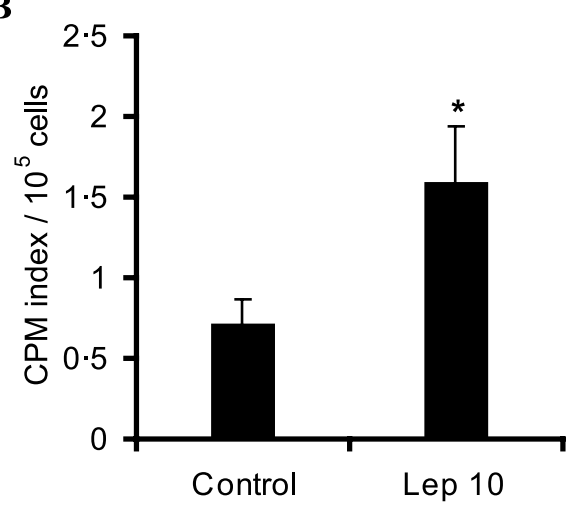

Figure 4 Effect of leptin on (A) intracellular ${ }^{14} \mathrm{C}$-fatty acid oxidation and (B) intracellular ${ }^{14} \mathrm{C}$-TG hydrolysis in adipocytes. Control=no leptin/no insulin; Lep $10=$ leptin $10 \mathrm{ng} / \mathrm{ml}$. Data are expressed as means \pm S.E.M. of 5 determinations. CPM index represents the relation between sample c.p.m./intracellular TG c.p.m. $\times 1000 .{ }^{*} P<0 \cdot 05$ compared with Control. 


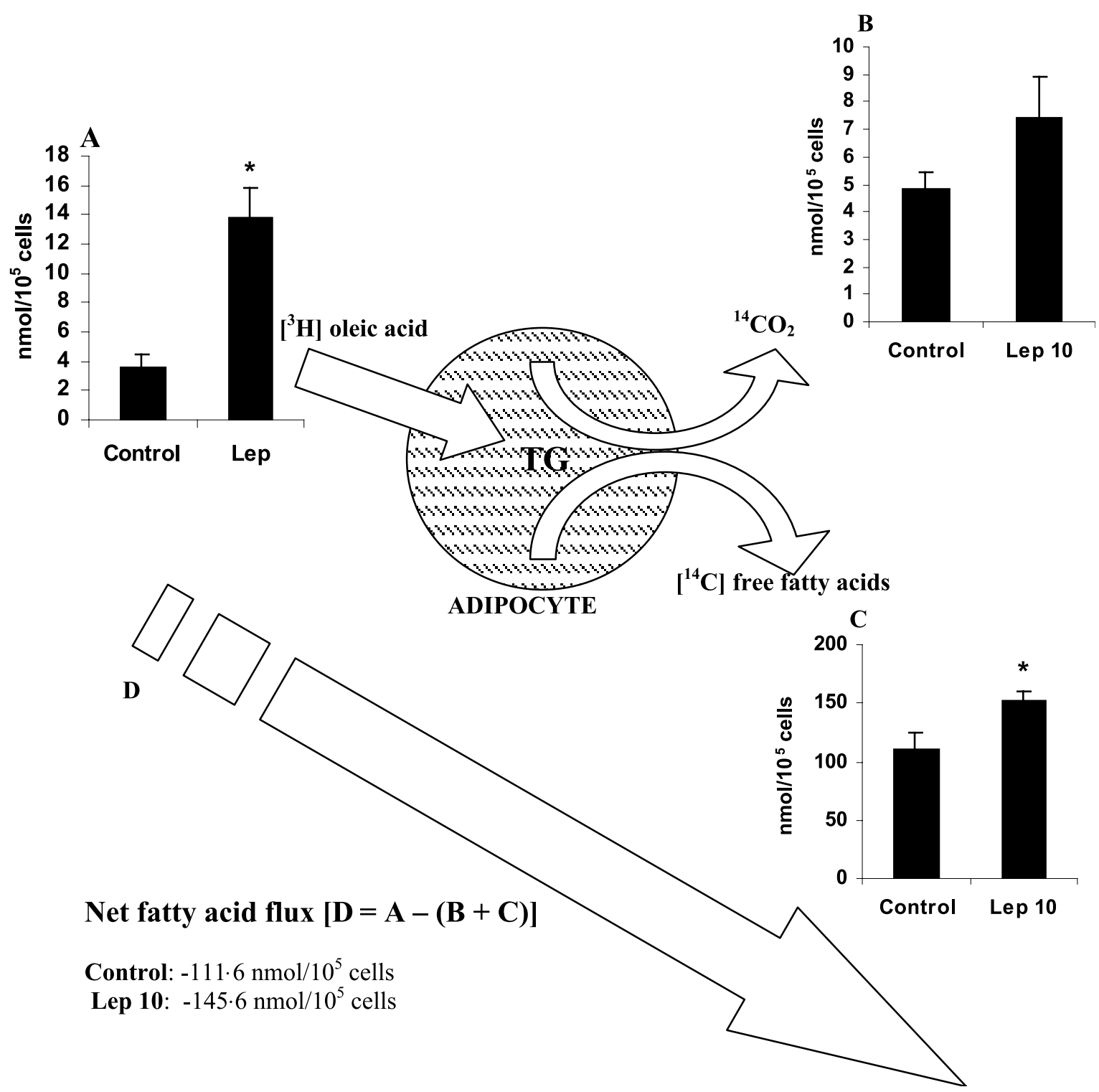

Figure 5 Effect of leptin on (A) $\left[9,10-{ }^{3} \mathrm{H}(\mathrm{N})\right]$ oleic acid incorporation into TG, (B) intracellular ${ }^{14} \mathrm{C}$-fatty acid oxidation, (C) intracellular ${ }^{14} \mathrm{C}$-TG hydrolysis and (D) fatty acid flux in adipocytes. Control=no leptin/no insulin; Lep $10=l$ eptin $10 \mathrm{ng} / \mathrm{ml}$. Data are expressed as means \pm S.E.M. of 5 determinations. ${ }^{*} P<0 \cdot 05$ compared with Control.

from glucose in adipocyes in vitro. These results are in accordance with earlier findings that adipocytes cultivated for $15 \mathrm{~h}$ with leptin present an impairment of insulinstimulated glucose transport and formation of glycogen and TG (Müller et al. 1997, Ceddia et al. 1998). In these latter studies, however, no distinction was made as to whether leptin inhibited the synthesis of glycerol or of the fatty acid moieties of TG, since only the incorporation of glucose into total lipids was determined (Ceddia et al. 1998). Our findings demonstrate that leptin down-regulates de novo fatty acid synthesis, which depends on the rate limiting enzymes acetyl-CoA carboxylase (ACC) and fatty acid synthase (FAS). These enzymes may be down-regulated by leptin, since it decreases the incorporation of acetic acid into lipids (Ceddia et al. 2000). Acetic acid is converted into acetyl-CoA by acetyl-CoA synthase, and from then on to malonyl-CoA and fatty acids by ACC and FAS respectively. Leptin has also been shown to inhibit ACC and FAS mRNA expression in adipocytes in vivo (Zhou et al. 1999) and in vitro (Wang et al. 1999a) and this could be the mechanism by which de novo lipogenesis was decreased in the present study. Furthermore, it has also been reported previously that malic enzyme and ATPcitrate lyase, which are also important enzymes for fatty 
acid synthesis, are down-regulated by leptin in isolated adipocytes (Fukuda \& Iritani 1999, Ceddia et al. 2000).

In our study, leptin stimulated acetic acid and oleic acid oxidation by $50 \%$ and $76 \%$ respectively. Acetic acid is a short chain fatty acid and is metabolized to $\mathrm{CO}_{2}$ by its conversion to acetyl-CoA followed by entry into the Krebs' cycle. The oxidation pathway of oleic acid, a long chain fatty acid, is different, since it must first be activated in the cytosol, transported across the mitochondrial membrane (via $\mathrm{CPT}$ ) and then converted to $\mathrm{CO}_{2}$ by the enzymes of fatty acid oxidation and the Krebs' cycle (Greville \& Tubbs 1968). Previous studies have demonstrated that leptin stimulates Krebs' cycle activity in adipocytes and skeletal muscle, leading to increased glucose and fatty acid oxidation in these tissues (Muoio et al. 1997, Ceddia et al. 1999c, 2000). Such effects have been attributed to a possible increase in UCP expression/ activity caused by leptin, which in turn would decrease the intracellular ATP/ADP and $\mathrm{NADH} / \mathrm{NAD}^{+}$ratios activating the enzymes of the Krebs' cycle (Ceddia et al. 1999c). In fact, it has been reported that leptin raises the expression of UCP-2 and the activity of citrate synthase in isolated adipocytes (Ceddia et al. 2000). The results of the present study, however, suggest that it is not only the Krebs' cycle activity that is stimulated by leptin, because the increment found in oleic acid oxidation (76\%) exceeded the one of acetic acid oxidation (50\%) under the same incubation conditions. Therefore, leptin may also activate $\mathrm{CPT}$ and/or the enzymes of long chain fatty acid oxidation (such as ACO) in the isolated cells as well. Up-regulation of CPT and ACO expression in adipocytes has been reported following in vivo leptin treatment (Zhou et al. 1999). Furthermore, CPT activity can be alosterically down-regulated by malonyl-CoA (McGarry 1998). Since leptin inhibits the fatty acid synthesis pathway, the intracellular malonyl-CoA concentration could be lower in these cells, leading to increased CPT activity and higher long-chain fatty acid oxidation rates.

As mentioned before, the oxidation of either $\left[{ }^{14} \mathrm{C}\right]$ oleate or $\left[{ }^{14} \mathrm{C}\right]$ acetate added to the incubation medium was significantly increased in adipocytes exposed to leptin. However, when cells were allowed to incorporate $\left[{ }^{14} \mathrm{C}\right]$ oleate into TG and then were subsequently incubated with leptin, despite the increase in the rate of lipolysis, no difference was found for ${ }^{14} \mathrm{CO}_{2}$ production between leptin-incubated adipocytes and controls. One possible explanation is that specific radioactivity of the intracellular TG pool of the adipocytes was too low and the experimental method would not be sensitive enough to detect a possible increase in ${ }^{14} \mathrm{CO}_{2}$ production induced by leptin. However, it seems unlikely that the methodology used would fail to detect changes in intracellular fatty acid oxidation while being able to identify an increase in $\mathrm{TG}$ hydrolysis induced by leptin, since the amount of radioactivity recovered as ${ }^{14} \mathrm{C}$-free fatty acids in the incubation medium (which represents TG hydrolysis) in the control group was only three times higher than the radioactivity recovered as ${ }^{14} \mathrm{CO}_{2}$ (c.p.m. index $/ 10^{5}$ cells of $0 \cdot 71 \pm 0 \cdot 16$ versus $0.23 \pm 0.03$ respectively) (Fig. 4). Based on these results, it seems that fatty acids entering isolated adipocytes are metabolized differently from fatty acids derived from the hydrolysis of the intracellular pool of TG in leptinincubated cells. Differential intracellular free fatty acid mobilization in adipocytes has previously been described by Edens et al. (1990). These authors have shown that fatty acids arising from intracellular TG hydrolysis must first leave the adipocyte and then re-enter the cell in order to be re-esterified into TG. In fact, in the last decades, several authors have provided evidence for the existence of metabolically distinct free fatty acid pools inside the adipose cell (Dole 1961, Vaughan et al. 1964). According to the results herein presented, leptin seems to favor exogenous fatty acid oxidation, while intracellular fatty acids derived from TG hydrolysis are preferentially released to the extracellular compartment. This could be a mechanism by which leptin improves fatty acid exportation from adipocytes to other tissues, such as skeletal muscle and liver, where a substantially higher amount of this substrate may be oxidized.

According to our data, leptin increased TG synthesis from oleic acid to an extent comparable with that of supra-physiological levels of insulin. At first, it seemed paradoxical that leptin, often considered an anti-obesity hormone, would favor TG synthesis in isolated adipocytes. We subsequently tested if the increased TG synthesis from oleic acid induced by leptin could be a result of the stimulation of fatty acid-TG cycling. Substrate cycling exists when two opposing non-equilibrium reactions are simultaneously active. They contribute to energy expenditure (through facultative thermogenesis), because energy utilization is required to drive both reactions (Tagliaferro et al. 1990). Cycling is also thought to increase sensitivity of controlling substrate flux through a metabolic pathway (Tagliaferro et al. 1990). In adipocytes, glucagon and noradrenaline stimulate fatty acid-TG cycling (Brooks et al. 1982). By this mechanism, intracellular fatty acids derived from TG hydrolysis are re-esterified into TG in a futile reaction, resulting in ATP consumption. If cells with an accelerated fatty acid-TG cycling were exposed to exogenous $\left[1-{ }^{14} \mathrm{C}\right]$-labeled fatty acid, an increase in its incorporation into TG would be expected to occur, since both TG synthesis and breakdown reactions would be active. However, according to our results, leptin failed to up-regulate fatty acid-TG cycling.

Since stimulation of fatty acid-TG cycling could not account for the increase in the incorporation of $\left[1-{ }^{14} \mathrm{C}\right]$ oleic acid into TG induced by leptin treatment of adipocytes, we investigated whether leptin altered fatty acid fluxes through these cells, i.e. leptin stimulated fatty acid incorporation into TG but also enhanced TG breakdown (fatty acid oxidation and/or exportation) to a greater extent, contributing therefore to an adipose reducing 
effect. Our first approach to this problem was to assess whether leptin stimulated intracellular TG breakdown. We performed experiments where isolated adipocytes had their intracellular TG previously labeled with $\left[1-{ }^{14} \mathrm{C}\right]$ oleic acid and were then incubated with leptin. At $10 \mathrm{ng} / \mathrm{ml}$, leptin did not increase the intracellular fatty acid oxidation, as previously mentioned. However, these cells presented an increase in free fatty acids release to the incubation medium. These results are in accordance with previous studies that evidenced a lipolytic effect of leptin in isolated adipocytes (Frühbeck et al. 1997, Wang et al. 1999a). Although free fatty acids release was not measured in those experiments, adipocytes incubated with leptin showed a higher glycerol release rate, which is compatible with an increase in TG hydrolysis observed in the present study. We then incubated previously ${ }^{14} \mathrm{C}$-labeled adipocytes in a medium containing $\left[9,10-{ }^{3} \mathrm{H}(\mathrm{N})\right]$ oleic acid in the presence and absence of leptin so as to measure, concomitantly and in absolute values, the amount of fatty acids incorporated into intracellular TG and the amount of intracellular fatty acids released as $\mathrm{CO}_{2}$ or free fatty acids (fatty acid fluxes). The net fatty acid efflux of adipocytes incubated with leptin exceeded that of controls in 34 nmols $/ 10^{5}$ cells (30\%). Therefore, although leptin increases the incorporation of oleic acid into intracellular TG, it increases intracellular TG breakdown and free fatty acids release to a greater extent, promoting a higher net fatty acid efflux than that which is observed in the control group.

Animals made hyperleptinemic by adenovirus infection have their adipose tissue depleted by a mechanism independent of the central nervous system (Wang et al. 1999b). Since no elevation in the circulating concentration of free fatty acids of these animals is observed, it has been assumed that leptin induces intracellular fatty acid oxidation (Shimabukuro et al. 1997). Furthermore, isolated white adipocytes incubated with $20 \mathrm{ng} / \mathrm{ml}$ leptin present an increase in glycerol release to the incubation medium without a proportional elevation in release of free fatty acids, indicating that probably the fatty acids are oxidized inside the adipocyte following TG hydrolysis (Wang et al. 1999a). It should be noted, however, that the oxidation of intracellular lipids in adipocytes stimulated by leptin has never been directly evaluated. Our results indicate that leptin does enhance fatty acid oxidation in white adipocytes. However, contrary to what has been inferred by in vivo observations and glycerol release experiments (Shimabukuro et al. 1997, Wang et al. 1999a), this effect is only observed with fatty acids taken up from the extracellular milieu. On the other hand, leptin modulates fatty acid fluxes in the white adipose tissue, leading to TG hydrolysis and release of fatty acids to the extracellular space. By extrapolating our in vitro data to in vivo situations, we could postulate that the main direct effect of leptin on fatty acid metabolism of white adipose cells is to enhance TG breakdown and offer free fatty acids to other tissues where they can be oxidized at higher rates, rather than stimulating its degradation inside the adipocyte, which is a mitochondria-poor cell type. The fact that rodents do not present a rise in the levels of circulating free fatty acids when exposed to hyperleptinemia (Shimabukuro et al. 1997) does not rule out the fatty acids flux shifting effects of leptin. In fact, these animals have higher levels of expression of enzymes of fatty acid oxidation in nonadipose cells (Zhou et al. 1997) and no alterations in the circulating free fatty acid concentrations should be expected if these tissues could oxidize increasing amounts of circulating fatty acids in a similar proportion to their increased release from the adipose tissue. Muoio et al. (1997) have recently demonstrated that skeletal muscles incubated with leptin present a higher exogenous fatty acid oxidation rate, which corroborates the idea of increased lipid oxidation in non-adipose cells stimulated by leptin. Furthermore, in a recent trial involving nine patients with lipodystropy, who often present severe deficiency of adipose cells, hypoleptinemia, hypertriglyceridemia, reduced insulin sensitivity and increased liver volume due to steatohepatitis, leptin replacement significantly reduced food intake, body weight, serum TG levels and insulin resistance. Liver volume was also lowered in the leptin-treated patients, possibly because of reduction of local TG stores. From the analysis of one patient, the authors suggest that the effects of leptin on TG metabolism are independent of decreased food intake (Oral et al. 2002). These results are consistent with the hypothesis that leptin induces TG breakdown in non-adipose cells, including the liver.

We propose therefore that, in vivo, leptin alters fatty acid flux in adipocytes, stimulating both TG synthesis and breakdown. As a result, free fatty acids are exported to non-adipose cells (such as skeletal muscle and liver), where they can be oxidized at a higher rate. De novo lipogenesis is inhibited by leptin, whereas exogenous fatty acid oxidation is enhanced. This peripheral mechanism of action described herein could contribute to the putative physiological role of leptin in lean animals preventing obesity development.

\section{Acknowledgements}

The authors are indebted to the technical assistance of $\mathrm{J} R$ Mendonça, G de Souza and C K Miyasaka. We would like to thank Amgen Inc., Thousand Oaks, CA, USA for kindly supplying leptin. This study was supported by FAPESP, CNPq, CAPES, and PRONEX (168/97).

\section{References}

Barzilai N, She L, Liu L, Wang J, Hu M, Vuguin P \& Rossetti L 1999 Decreased visceral adiposity accounts for leptin effect on hepatic but not peripheral insulin action. American Journal of Physiology 277 E291-E298. 
Brooks B, Arch JRS \& Newsholme EA 1982 Effects of hormones on the rate of the triacylglycerol/fatty acid substrate cycle in adipocytes and epididymal fat pads. FEBS Letters 146 327-330.

Ceddia RB, William Jr WN, Lima FB \& Curi R 1998 Leptin inhibits insulin-stimulated incorporation of glucose into lipids and stimulates glucose decarboxylation in isolated rat adipocytes. Journal of Endocrinology 158 R7-R9.

Ceddia RB, Lopes G, Souza HM, Borba-Murad GR, William Jr WN, Bazotte RB \& Curi R 1999a Acute effects of leptin on glucose metabolism of in situ rat perfused livers and isolated hepatocytes. International Journal of Obesity 23 1207-1212.

Ceddia RB, William Jr WN, Carpinelli AR \& Curi R $1999 b$ Modulation of insulin secretion by leptin. General Pharmacology 32 233-237.

Ceddia RB, William Jr WN \& Curi R 1999c Comparing effects of leptin and insulin on glucose metabolism in skeletal muscle: evidence for a physiological effect of leptin on glucose uptake and decarboxylation. International Journal of Obesity 23 75-82.

Ceddia RB, William Jr WN, Lima FB, Flandin P, Curi R \& Giacobino JP 2000 Leptin stimulates uncoupling protein-2 mRNA expression and Krebs' cycle activity and inhibits lipid synthesis in isolated rat white adipocytes. European Journal of Biochemistry 267 5952-5958.

Coppack SW, Jensen MD \& Miles JM 1994 In vivo regulation of lipolysis in humans. Journal of Lipid Research 35 177-193.

DiGirolamo M, Medlinger S \& Fertig JW 1971 A simple method to determine fat cell size and number in four mammalian species. American Journal of Physiology 221 850-858.

Dole VP 1961 The fatty acid pool in adipose tissue. Journal of Biological Chemistry 236 3121-3124.

Dole VP \& Meirnertz H 1960 Microdetermination of long chain fatty acids in plasma and tissues. Journal of Biological Chemistry 235 2595-2599.

Edens NK, Leibel RL \& Hirsh J 1990 Mechanism of free fatty acid re-esterification in human adipocytes in vitro. Journal of Lipid Research 31 1423-1431.

Friedman JM \& Halaas JL 1998 Leptin and the regulation of body weight in mammals. Nature 395 763-770.

Frühbeck G, Aguado M \& Martínez JÁ 1997 In vitro lipolytic effect of leptin on mouse adipocytes: evidence for a possible autocrine/ paracrine role of leptin. Biochemical and Biophysical Research Communications 240 590-594.

Frühbeck G, Aguado M, Gómez-Ambrosi J \& Martínez JÁ 1998 Lipolytic effect of in vivo leptin administration on adipocytes of lean and $\mathrm{ob} / \mathrm{ob}$ mice, but not $\mathrm{db} / \mathrm{db}$ mice. Biochemical and Biophysical Research Communications 250 99-102.

Fukuda H \& Iritani N 1999 Regulation of ATP citrate-lyase gene expression in hepatocytes and adipocytes in normal and genetically obese rats. Journal of Biochemistry 126 437-444.

Greville GD \& Tubbs PK 1968 The catabolism of long chain fatty acids in mammalian tissues. Essays in Biochemistry 4 155-212.

Homem de Bittencourt Jr PI \& Curi R 1998 Transfer of cholesterol from macrophages to lymphocytes in culture. Biochemistry and Molecular Biology International 44 347-362.

Junga RL 1968 Fatty acid synthesis in adipose tissue incubated in tritiated water. Biochemistry 7 3708-3717.

Levin N, Nelson C, Gurney A, Vandlen R \& Sauvage F 1996 Decreased food intake does not completely account for adiposity reduction after ob protein infusion. PNAS 93 1726-1730.

Luoh SM, Di Marco F, Levin N, Armanini M, Xie MH, Nelson C, Bennett GL, Williams M, Spencer SA, Gurney A \& de Sauvage FJ
1997 Cloning and characterization of a human leptin receptor using a biologically active leptin immunoadhesin. Journal of Molecular Endocrinology 18 77-85.

McGarry JD 1998 Glucose - fatty acid interactions in health and disease. American Journal of Clinical Nutrition 67 500S-504S.

McGowan MW, Artiss JD, Strandbergh DR \& Zak B 1983 A peroxidase-coupled method for the colorimetric determination of serum triglycerides. Clinical Chemistry 29 538-542.

Müller G, Ertl J, Gerl M \& Preibish G 1997 Leptin impairs metabolic actions of insulin in isolated rat adipocytes. Journal of Biological Chemistry 272 10585-10593.

Muoio DM, Dohn GL, Fiedorek Jr FT, Tapascott EB \& Coleman RA 1997 Leptin directly alters lipid partitioning in skeletal muscle. Diabetes 46 1360-1363.

Oral EA, Simha V, Ruiz E, Andewelt A, Premkumar A, Snell P, Wagner AJ, DePaoli AM, Reitman ML, Taylor SI, Gorden P \& Garg A 2002 Leptin-replacement therapy for lipodystrophy. New England Journal of Medicine 346 570-578.

Rodbell M 1964 Metabolism of isolated fat cells: effects of hormones and glucose metabolism and lipids. Journal of Biological Chemistry 177 176-197.

Sarmiento U, Benson B, Kaufman S, Ross L, Qi M, Scully S \& DiPalma C 1997 Morphologic and molecular changes induced by recombinant human leptin in the white and brown adipose tissues of C57BL/6 mice. Laboratory Investigation 77 243-256.

Shimabukuro M, Koyama K, Chen G, Wang MY, Trieu F, Lee Y, Newgard CB \& Unger RH 1997 Direct antidiabetic effect of leptin through triglyceride depletion of tissues. PNAS $\mathbf{9 4}$ 4637-4641.

Stein Y \& Stein O 1962 The incorporation and disappearance of fatty acids in the rat epididymal fat pad studied by the in vivo incubation technique. Biochimica et Biophysica Acta 60 58-71.

Tagliaferro AR, Dobbin S, Curi R, Leighton B, Meeker LD \& Newsholme EA 1990 Effects of diet and exercise on the in vivo rates of the triglyceride-fatty acid cycle in adipose tissue and muscle of the rat. International Journal of Obesity 14 957-971.

Vaughan M, Steinberg D \& Pittman R 1964 On the interpretation of studies measuring uptake and esterification of $\left[1-{ }^{14} \mathrm{C}\right]$ palmitic acid by rat adipose tissue in vitro. Biochimica et Biophysica Acta $\mathbf{8 4}$ $154-166$.

Wang MY, Lee Y \& Unger RH 1999a Novel form of lipolysis induced by leptin. Journal of Biological Chemistry 274 17541-17544.

Wang ZW, Zhou YT, Kakuma T, Lee Y, Higa M, Kalra SP, Dube MG, Kalra PS \& Unger RH 19996 Comparing the hypothalamic and extrahypothalamic actions of endogenous hyperleptinemia. PNAS 96 10373-10378.

Wang ZW, Zhou YT, Lee Y, Higa M, Kalra SP \& Unger RH 1999c Hyperleptinemia depletes fat from denervated fat tissue. Biochemical and Biophysical Research Communications 260 653-657.

Zhou YT, Shimabukuro M, Koyama K, Lee Y, Wang MY, Trieu F, Newgard CB \& Unger RH 1997 Induction by leptin of uncoupling protein-2 and enzymes of fatty acid oxidation. PNAS 94 6386-6390

Zhou YT, Wang ZW, Higa M, Newgard CB \& Unger RH 1999 Reversing adipocyte differentiation: implication for treatment of obesity. PNAS 96 2391-2395.

Received in final form 12 August 2002

Accepted 14 August 2002 